\title{
In vitro and in vivo effects of antimicrobial agents on viability of Cryptobia salmositica (Sarcomastigophora: Kinetoplastida)
}

\author{
Philip T. Thomas, Patrick T. K. Woo* \\ Department of Zoology, University of Guelph, Guelph, Ontario, Canada NIG 2Wl
}

\begin{abstract}
Cryptobia salmositica (Sarcomastigophora: Kinetoplastida) from blood of infected rainbow trout (blood forms) or cultures (culture forms) rounded up when incubated in vitro with a combination of Penicillin, Streptomycin and Amphotericin B (antimicrobial agents, AM). Trypan blue dye exclusion test showed that slender forms did not take up the dye whereas many round forms became coloured as incubation proceeded. Culture forms were more susceptible to AM than blood forms. Washing the blood forms prior to incubation with AM increased their susceptibility, but they were still more resistant than unwashed or washed culture forms. Trypan blue had a protective effect on viability of both blood and culture forms exposed to AM. Parasites exposed to AM were still infective when inoculated into rainbow trout. Injection of AM into fish infected with blood or culture forms did not affect the parasitaemias. Although $C$. salmositica and trypanosomes are phylogenetically related, AM did not affect trypanosomes (mammalian and piscine).
\end{abstract}

\section{INTRODUCTION}

Cryptobia salmositica is a pathogenic haemoflagellate of salmonids on the west coast of North America. Infected rainbow trouts develop anorexia, exophthalmia, abdominal distension with ascites, general oedema, splenomegaly, and a microcytic and hypochromic anaemia (Woo 1979, 1987, Thomas \& Woo 1990a). Fish that recover from the infection are refractive to challenge (Jones \& Woo 1987). Elimination of the parasite appears to be due to both humoral and cell-mediated immune responses of the host (Woo 1979, 1987, Jones \& Woo 1987, Thomas \& Woo 1990b).

Cryptobia salmositica is phylogenetically related to the trypanosomes (Order: Kinetoplastida) and shares many similar host-parasite relationships with the pathogenic mammalian trypanosomes. For example, $C$. salmositica causes (i) immunodepression in the host (Jones \& Woo 1987), (ii) an anaemia that is caused partly by excretory or secretory products from the parasite (Woo 1979, Thomas \& Woo 1988, 1989) and (iii) anorexia (Thomas \& Woo 1990a). There is, at present,

\footnotetext{
- Addressee for correspondence
}

no chemotherapy against cryptobiosis and the common trypanocidal drugs are not effective (see Woo 1987).

Antimicrobial agents (AM) are not known to affect the viability of trypanosomes, consequently they are often added to cultures, especially during the primary isolation of the parasite. However, little is known about the effects of AM on the viability of Cryptobia spp. In a preliminary in vitro study we found that a commercially available combination of AM (Penicillin, Streptomycin and Amphotericin B) killed C. salmositica at the recommended dose. The purpose of the present study was to further examine the cryptobiacidal effects of the AM on C. salmositica. This study is part of an ongoing programme to develop to protect fish from cryptobiosis.

\section{MATERIALS AND METHODS}

Maintenance of Cryptobia salmositica. C. salmositica was cultured in Minimum Essential Medium containing Hank's salts and L-glutamine and supplemented with foetal bovine serum and Hepes (Woo 1990). Parasites were isolated from the blood of an infected rainbow trout at 3 wk post-infection and, after determining the parasitaemia, $0.1 \mathrm{ml}$ of the blood was inoculated into LUX culture flasks (Miles Scientific, 
Naperville, Illinois, USA) containing $10 \mathrm{ml}$ of the medium. The flasks were kept at $10^{\circ} \mathrm{C}$ in a slanting position. After $5 \mathrm{wk}$, the parasites (without the contaminating erythrocytes) were subcultured into another flask and incubated at $10^{\circ} \mathrm{C}$. Four weeks later the parasites were harvested and used in the present study.

Antimicrobial agents (AM). The stock AM solution contained 10000 units $\mathrm{ml}^{-1}$ Penicillin G sodium, 10000 $\mu \mathrm{g} \mathrm{ml} \mathrm{ml}^{-1}$ Streptomycin sulphate and $25 \mu \mathrm{g} \mathrm{ml} \mathrm{ml}^{-1}$ Amphotericin $\mathrm{B}$ as Fungizone ${ }^{\mathrm{R}}$. The recommended dose (RD) is $1 \mathrm{ml} / 100 \mathrm{ml}$ medium (GIBCO Laboratories, Burlington, Ontario, Canada). The following concentrations were used: $\mathrm{RD}, 4 \times \mathrm{RD}$, dilutions of $1: 2,1: 4,1: 8$ using cold-blooded vertebrate Ringer's solution (CBVR), and no AM.

Trypan blue (TB) dye exclusion test. Washed (centrifugation with $\mathrm{CBVR}$ at $13200 \times \mathrm{g}$ for $5 \mathrm{~min}$ at $4{ }^{\circ} \mathrm{C}$ ) or unwashed Cryptobia salmositica from the blood of an infected rainbow trout or from cultures were incubated with AM ( $4 \times$ RD, RD, and no AM) and TB (10\% v/v) at $10^{\circ} \mathrm{C}$. Fifty parasites were randomly counted every 30 min for $4 \mathrm{~h}$ using a microscope and the parasites were categorized as coloured slender, non-coloured slender, coloured round and non-coloured round.

Protection of viability of AM-exposed Cryptobia salmositica by TB. (i) Cryptobia salmositica (blood or culture forms; unwashed or washed) was incubated at $10^{\circ} \mathrm{C}$ with $\mathrm{AM}$ solution $(4 \times \mathrm{RD}, \mathrm{RD}$ and no $\mathrm{AM})$ containing TB or no TB. Fifty parasites were randomly counted every $30 \mathrm{~min}$ for $4 \mathrm{~h}$ and categorized as above.

(ii) Cryptobia salmositica from a 5 wk-old second subculture were incubated with $10 \%(\mathrm{v} / \mathrm{v})$ TB for $1 \mathrm{~h}$ at $10^{\circ} \mathrm{C}$. Parasites incubated with CBVR served as control. The parasites were then washed (centrifugation at $13200 \times g$ for $5 \mathrm{~min}$ at $4^{\circ} \mathrm{C}$ ), resuspended in CBVR and incubated with $4 \times \mathrm{RD}$ of AM. Fifty parasites were randomly examined every hour for $3 \mathrm{~h}$ and numbers of slender and round forms were noted.

Protection of viability of AM-exposed Cryptobia salmositica by heat-inactivated foetal bovine serum. Cryptobia salmositica subcultured for $92 \mathrm{wk}$ was washed and resuspended in either CBVR or CBVR containing $25 \%$ heat-inactivated foetal bovine serum and incubated at $10^{\circ} \mathrm{C}$ for $3 \mathrm{~h}$ with $\mathrm{AM}(4 \times \mathrm{RD}, \mathrm{RD}$, and no AM). Samples of the suspensions (10 $\mu \mathrm{l})$ were withdrawn every hour and mixed with $2.5 \mu \mathrm{l}$ TB on a glass slide. Fifty parasites were randomly counted and categorized as above.

Infectivity of AM-exposed Cryptobia salmositica. Approximately 200000 culture forms of Cryptobia salmositica in $200 \mu \mathrm{l}$ of CBVR was added to each of 15 wells in a 96-well microtitre plate (Dynatech Laboratories Inc., Alexandria, Virginia, USA) kept at $10^{\circ} \mathrm{C}$. The following concentrations of the AM (in 3 replicates) were added to the wells containing the parasite: RD, dilutions of $1: 2,1: 4,1: 8$ and no AM. The final volume in each well was $202 \mu \mathrm{l}$. The parasite suspension was incubated at $10^{\circ} \mathrm{C}$ for $3 \mathrm{~h}$. Each well was examined using an inverted microscope and the contents inoculated intraperitoneally (i.p.) into a rainbow trout (about $300 \mathrm{~g}$ weight; 3 fish for each of the 5 concentrations of AM). The fish were maintained in fibre-glass tanks with aerated free-flowing well water at $10^{\circ} \mathrm{C}$ and fed commercial trout pellets (Martin's Feed Mills, Elmira, Ontario, Canada) once a day. Parasitaemias in infected fish were determined at 3, 7 and 8 wk post-infection using the haematocrit centrifuge method (Woo \& Wehnert 1983) or by haemacytometer count (Archer 1965).

Parasitaemias in AM-treated rainbow trout. Twentyfour rainbow trout ca $100 \mathrm{~g}$ each) were inoculated i.p. with ca 100000 blood forms of Cryptobia salmositica per fish. Six fish were injected i.p. with RD of AM at $1 \mathrm{wk}$ post-infection; another 6 fish (controls) were injected with CBVR. At 2 wk post-infection, 6 of the remaining 12 fish were injected with $\mathrm{AM}$ and the rest with CBVR. The RD for fish was determined as follows: the blood volume of fish was estimated to be ca $4 \mathrm{ml}$; consequently, $0.04 \mathrm{ml}$ of AM (in $0.06 \mathrm{ml} \mathrm{CBVR}$ ) was injected into each fish.

Another group of 24 rainbow trout were inoculated with ca 100000 culture forms per fish and AM or CBVR was injected at Weeks 1 and 2 post-infection as above.

Blood $(0.2 \mathrm{ml})$ was withdrawn from all fish by cardiac puncture at Weeks 5,7 and 8 post-infection and the parasitaemias were determined using a haemacytometer (Archer 1965).

Statistics. Parasitaemias in fish during different weeks post-infection were compared using Student $t$ test after log transformation of the parasite counts. A significant difference was indicated by $\mathrm{p} \leq 0.05$.

\section{RESULTS}

\section{TB dye exclusion test on Cryptobia salmositica}

None of the slender forms was stained by TB. The number of coloured forms (round) increased with length of incubation while the number of slender forms decreased (Tables $1 \& 2$ ). The increase in number of coloured forms with the progression of incubation was greater in culture forms than in blood forms (Tables 1 \& 2 ). Fewer slender forms and more round forms were present in parasite suspension containing $4 \times \mathrm{RD}$ when compared to parasite suspensions containing $\mathrm{RD}$ or no AM. Washing the blood forms prior to incubation with AM resulted in more round forms and fewer slender forms than those in the unwashed group at the end of the incubation period (Table 3 ). 
Table 1. Cryptobia salmositica. Incubation of washed blood and culture forms with recommended dose of antimicrobial agents and with $(+)$ or without $(-)$ Trypan blue. Incub: incubation; TB: Trypan blue; C Ro: coloured round; N Ro: noncoloured round; n Sl: non-coloured slender; na: not applicable

\begin{tabular}{|c|c|c|c|c|c|c|c|}
\hline \multirow{2}{*}{$\begin{array}{l}\text { Incub. } \\
\text { (h) }\end{array}$} & \multirow[t]{2}{*}{ TB } & \multicolumn{3}{|c|}{ Blood forms } & \multicolumn{3}{|c|}{ Culture forms } \\
\hline & & N Sl & C Ro & N Ro & $\mathrm{N} \mathrm{Sl}$ & C Ro & N Ro \\
\hline \multirow[t]{2}{*}{0.0} & + & 50 & 0 & 0 & 50 & 0 & 0 \\
\hline & - & 50 & na & 0 & 50 & na & 0 \\
\hline \multirow[t]{2}{*}{0.5} & + & 50 & 0 & 0 & 44 & 0 & 6 \\
\hline & - & 50 & na & 0 & 29 & na & 21 \\
\hline \multirow{2}{*}{1.0} & + & 50 & 0 & 0 & 46 & 1 & 3 \\
\hline & - & 50 & na & 0 & 8 & na & 42 \\
\hline \multirow[t]{2}{*}{1.5} & + & 50 & 0 & 0 & 43 & 2 & 5 \\
\hline & - & 46 & na & 4 & 3 & na & 47 \\
\hline \multirow[t]{2}{*}{2.0} & + & 50 & 0 & 0 & 43 & 5 & 2 \\
\hline & - & 13 & na & 37 & 0 & na & 50 \\
\hline \multirow[t]{2}{*}{2.5} & + & 46 & 1 & 3 & 40 & 4 & 6 \\
\hline & - & 12 & na & 38 & 0 & na & 50 \\
\hline \multirow[t]{2}{*}{3.0} & + & 46 & 0 & 4 & 44 & 5 & 1 \\
\hline & - & 12 & na & 38 & 0 & na & 50 \\
\hline \multirow[t]{2}{*}{3.5} & + & 46 & 1 & 3 & 42 & 8 & 0 \\
\hline & - & 8 & na & 42 & 0 & na & 50 \\
\hline \multirow[t]{2}{*}{4.0} & + & 42 & 3 & 5 & 30 & 13 & 7 \\
\hline & - & 7 & na & 43 & 1 & na & 49 \\
\hline
\end{tabular}

\section{Protection of viability of AM-exposed Cryptobia salmositica by TB}

Parasite-AM suspensions containing TB had fewer round forms and more slender forms than those without TB at the end of the incubation period (Table 3 ).

\section{Effects of AM on Cryptobia salmositica that had prior exposure to TB}

The numbers of slender and round forms were similar in suspensions of the parasite that had prior exposure or no prior exposure to TB (data not shown).

\section{Protection of viability of AM-exposed Cryptobia salmositica by heat-inactivated foetal bovine serum}

Parasite-AM suspensions containing foetal bovine serum had fewer round forms and more slender forms than those without foetal bovine serum (Table 4).

\section{Infectivity of AM-exposed Cryptobia salmositica}

Cryptobia salmositica incubated with the RD and $1: 2$ dilution of AM rounded up in $3 \mathrm{~h}$; no slender forms
Table 2. Cryptobia salmositica. Incubation of washed blood and culture forms with cold-blooded vertebrate Ringer's solution (no antimicrobial agents) and with $(+)$ or without $(-)$ Trypan blue. Abbreviations as for Table 1

\begin{tabular}{|c|c|c|c|c|c|c|c|}
\hline \multirow{2}{*}{$\begin{array}{l}\text { Incub. } \\
\text { (h) }\end{array}$} & \multirow{2}{*}{ TB } & \multicolumn{3}{|c|}{ Blood forms } & \multicolumn{3}{|c|}{ Culture forms } \\
\hline & & $\mathrm{N} \mathrm{Sl}$ & C Ro & N Ro & $\mathrm{N} \mathrm{Sl}$ & C Ro & N Ro \\
\hline \multirow[t]{2}{*}{0.0} & + & 50 & 0 & 0 & 43 & 0 & 7 \\
\hline & - & 50 & na & 0 & 42 & na & 8 \\
\hline \multirow[t]{2}{*}{0.5} & + & 50 & 0 & 0 & 42 & 1 & 7 \\
\hline & - & 50 & na & 0 & 48 & na & 2 \\
\hline \multirow[t]{2}{*}{1.0} & + & 50 & 0 & 0 & 40 & 3 & 7 \\
\hline & - & 50 & na & 0 & 44 & na & 6 \\
\hline \multirow[t]{2}{*}{1.5} & + & 50 & 0 & 0 & 40 & 4 & 6 \\
\hline & - & 50 & na & 0 & 42 & na & 8 \\
\hline \multirow[t]{2}{*}{2.0} & + & 50 & 0 & 0 & 38 & 5 & 7 \\
\hline & - & 50 & na & 0 & 44 & na & 6 \\
\hline \multirow[t]{2}{*}{2.5} & + & 48 & 1 & 1 & 35 & 8 & 7 \\
\hline & - & 49 & na & 1 & 42 & na & 8 \\
\hline \multirow[t]{2}{*}{3.0} & + & 46 & 1 & 3 & 32 & 10 & 8 \\
\hline & - & 49 & na & 1 & 39 & na & 11 \\
\hline \multirow[t]{2}{*}{3.5} & + & 48 & 0 & 2 & 37 & 6 & 7 \\
\hline & - & 49 & na & 1 & 36 & ná & 14 \\
\hline \multirow[t]{2}{*}{4.0} & + & 50 & 0 & 0 & 41 & 4 & 5 \\
\hline & - & 49 & na & 1 & 40 & na & 10 \\
\hline
\end{tabular}

were observed. Numerous slender forms were present in wells containing 1:4, 1:8 AM and no AM.

Fourteen of 15 fish inoculated with AM/CBVRexposed parasites were infected. Two fish inoculated with parasites exposed to RD of AM had no detectable parasitaemias (using the haematocrit centrifuge method) at 3 wk post-infection, but developed parasitaemias high enough to be counted using the haemacytometer at Weeks 7 and 8 post-infection.

\section{Parasitaemias in AM-treated rainbow trout}

Rainbow trout infected with Cryptobia salmositica (blood or culture forms) and injected with RD of AM or CBVR at 1 and 2 wk post-infection had parasitaemias that were not significantly different from each other's at Weeks 5,7 and 8 post-infection.

\section{DISCUSSION}

Viable cells do not take up TB whereas non-viable cells do (Phillips 1973). Only round forms took up the dye and the number of coloured round forms increased with length of incubation with AM (Table 1). This indicates that AM transforms the normal infective slen- 
Table 3. Cryptobia salmositica. Number of slender and round forms of washed parasites from blood or culture after exposure to antimicrobial agents with or without Trypan blue for $4 \mathrm{~h}$. AM: antimicrobial agents; RD: recommended dose. Numbers within parenthesis were obtained from unwashed parasites

\begin{tabular}{|c|c|c|c|c|c|}
\hline \multirow{2}{*}{$\begin{array}{l}\text { Dose } \\
\text { of AM }\end{array}$} & \multirow{2}{*}{$\begin{array}{l}\text { Source of } \\
\text { parasite }\end{array}$} & \multicolumn{2}{|c|}{ With Trypan blue } & \multicolumn{2}{|c|}{ Without Trypan blue } \\
\hline & & Slender & Round & Slender & Round \\
\hline \multirow[t]{2}{*}{ Nil } & Blood & 50 & 0 & 49 & 1 \\
\hline & Culture & 41 & 9 & 40 & 10 \\
\hline \multirow[t]{2}{*}{$\mathrm{RD}$} & Blood & 42 & 8 & 7 & 43 \\
\hline & Culture & 30 & 20 & 1 & 49 \\
\hline \multirow[t]{2}{*}{$4 \times \mathrm{RD}$} & Blood & $\begin{array}{c}35 \\
(44)\end{array}$ & $\begin{array}{l}15 \\
(6)\end{array}$ & $\begin{array}{c}0 \\
(36)\end{array}$ & $\begin{array}{c}50 \\
(14)\end{array}$ \\
\hline & Culture & 19 & 31 & 0 & 50 \\
\hline
\end{tabular}

Table 4. Cryptobia salmositica. Incubation with antimicrobial agents (AM) in cold-blooded vertebrate Ringer's solution (CBVR) or CBVR and foetal bovine serum followed by Trypan blue staining. RD: recommended dose; other abbreviations as in Table 1. Numbers within parenthesis were obtained from parasites in CBVR-foetal bovine serum-AM suspensions

\begin{tabular}{|c|c|c|c|c|c|c|c|c|c|}
\hline \multirow{2}{*}{$\begin{array}{l}\text { Incub. } \\
\text { (h) }\end{array}$} & \multicolumn{3}{|c|}{$4 \times \mathrm{RD}$} & \multicolumn{3}{|c|}{$\mathrm{RD}$} & \multicolumn{3}{|c|}{ No AM } \\
\hline & N Sl & C Ro & N Co & N Sl & C Ro & N Co & N Sl & C Ro & N Co \\
\hline 0.0 & $\begin{array}{c}29 \\
(27)\end{array}$ & $\begin{array}{c}14 \\
(10)\end{array}$ & $\begin{array}{c}7 \\
(13)\end{array}$ & $\begin{array}{c}36 \\
(38)\end{array}$ & $\begin{array}{c}9 \\
(7)\end{array}$ & $\begin{array}{c}5 \\
(5)\end{array}$ & $\begin{array}{c}43 \\
(39)\end{array}$ & $\begin{array}{c}2 \\
(2)\end{array}$ & $\begin{array}{c}5 \\
(9)\end{array}$ \\
\hline 1.0 & $\begin{array}{c}1 \\
(7)\end{array}$ & $\begin{array}{c}22 \\
(20)\end{array}$ & $\begin{array}{c}27 \\
(23)\end{array}$ & $\begin{array}{c}7 \\
(32)\end{array}$ & $\begin{array}{l}22 \\
(8)\end{array}$ & $\begin{array}{c}21 \\
(10)\end{array}$ & $\begin{array}{c}40 \\
(39)\end{array}$ & $\begin{array}{c}6 \\
(3)\end{array}$ & $\begin{array}{c}4 \\
(8)\end{array}$ \\
\hline 2.0 & $\begin{array}{c}0 \\
(3)\end{array}$ & $\begin{array}{c}32 \\
(16)\end{array}$ & $\begin{array}{c}18 \\
(31)\end{array}$ & $\begin{array}{c}0 \\
(31)\end{array}$ & $\begin{array}{l}23 \\
(6)\end{array}$ & $\begin{array}{c}27 \\
(13)\end{array}$ & $\begin{array}{c}41 \\
(41)\end{array}$ & $\begin{array}{c}4 \\
(4)\end{array}$ & $\begin{array}{c}5 \\
(5)\end{array}$ \\
\hline 3.0 & $\begin{array}{c}0 \\
(3)\end{array}$ & $\begin{array}{c}30 \\
(20)\end{array}$ & $\begin{array}{c}20 \\
(27)\end{array}$ & $\begin{array}{c}0 \\
(6)\end{array}$ & $\begin{array}{c}23 \\
(17)\end{array}$ & $\begin{array}{c}27 \\
(27)\end{array}$ & $\begin{array}{c}40 \\
(40)\end{array}$ & $\begin{array}{c}4 \\
(4)\end{array}$ & $\begin{array}{c}6 \\
(6)\end{array}$ \\
\hline
\end{tabular}

der forms to the round forms and the parasites take up TB as their viability is lost. The rounding up of the parasite appears to be a response to adverse environmental conditions. For example, rounding up of the parasites occurred when the ambient temperature was raised from the optimal $10^{\circ} \mathrm{C}$ to $21^{\circ} \mathrm{C}$ (unpubl.). Neither Trypanosoma brucei brucei nor piscine trypanosomes (e.g. T. catostomi, T. phaleri) were affected by RD of AM (Jones \& Woo unpubl.). Similarly, the common trypanocidal drugs were ineffective against Cryptobia salmositica (see Woo 1987). These observations indicate some basic differences between these related groups of parasites.

Parasites from culture were more susceptible to the AM than those from blood (Tables 1 \& 3). It is known that the culture forms are less virulent and do not cause disease in rainbow trout (Woo \& Li 1990). Also, the culture forms elicit a milder delayed type hypersensitivity reaction in rainbow trout than the blood forms (unpubl.). It is likely that the above differences between the 2 strains are due to differences in their surface properties. The increased susceptibility of culture forms (washed or unwashed) to AM in comparison to blood forms (washed or unwashed) (Table 3) supports the above hypothesis.

Washing the blood forms increased their susceptibility to AM (i.e. there were more round forms and fewer slender forms at the end of the incubation period in washed parasites in comparison to the unwashed group). This difference was not observed between washed and unwashed culture forms (Table 3). Evidently, some components from the host blood protected the viability of the blood forms. There is some evidence that the protective components are in the serum fraction of blood (Table 4). Also rainbow trout injected with $\mathrm{RD}$ of AM or CBVR at Weeks 1 and 2 post-infection had parasitaemias that were not significantly different from each other's in subsequent weeks. Although susceptibility of blood forms to AM increased after washing, they were still more resistant to AM than unwashed or washed culture forms (Table 3).

When parasites were incubated with TB, washed and exposed to AM, the number of round forms was not different from that observed when parasites were incu- 
bated with CBVR, washed and exposed to AM. This indicates that the 'protective' effect of TV is by neutralizing the effects of AM rather than by altering the parasite surface.

Although no slender forms were observed in microtitre wells containing RD or 1:2 dilution of AM after $3 \mathrm{~h}$, all fish (except one inoculated with 1:2 AM) developed infection. This indicates that at least some of the round forms were infective. Also, not all round forms were stained after $3 \mathrm{~h}$ of incubation with AM (Tables 1 \& 2). Since no slender forms were observed in the microtitre wells with RD or 1:2 AM, we suggest that viable round forms (non-coloured) established the infection in the fish.

The viable round forms have a longer pre-patent period than the slender forms. Two of 3 fish inoculated with parasites previously exposed to RD of AM had no detectable parasitaemias at 3 wk post-infection; all fish that were inoculated with parasites exposed to lesser concentrations of AM or no AM had detectable parasitaemias at $3 \mathrm{wk}$ post-infection. Nevertheless, all 3 fish that received Crytobia salmositica exposed to RD of AM had high parasitaemias comparable to that of other groups of infected fish at 7 and 8 wk post-infection.

We conclude that the viability of Cryptobia salmositica is adversely affected by in vitro exposure to AM. However, the effectiveness of AM for chemotherapy is doubtful as 'host-derived factors' protect the parasites. This study also indicates some basic differences between $C$. salmositica and the trypanosomes.

Acknowledgement. This study was supported by a grant from the Natural Sciences and Engineering Research Council of Canada to Patrick T. K. Woo.

Responsible Subject Editor: W. Körting, Hannover, Germany

\section{LITERATURE CITED}

Archer, R. K. (1965). Haematological techniques for use on animals. Blackwell Scientific Publications, Oxford

Jones, S. R. M., Woo, P. T. K. (1987). The immune response of rainbow trout, Salmo gairdneri Richardson, to the haemoflagellate Cryptobia salmositica Katz, 1951. J. Fish Dis. 10: 395-402

Phillips, H. J. (1973). Dye exclusion test for cell viability. In: Kruse, P. K., Patterson, M. K. (eds.) Tissue culture methods and application. Academic Press, New York p. 406-408

Thomas, P. T., Woo, P. T. K. (1988). Cryptobia salmositica: an in vitro and vivo study on the mechanism of anaemia in infected rainbow trout, Salmo gairdneri Richardson. J. Fish Dis. 11: 425-431

Thomas, P. T., Woo, P. T. K (1989). An in vitro study on the haemolytic components from Cryptobia salmositica (Sarcomastigophora: Kinetoplastida). J. Fish. Dis. 12: 389-393

Thomas, P. T., Woo, P. T. K. (1990a). Anorexia in Oncorhynchus mykiss infected with Cryptobia salmositica (Sarcomastigophora: Kinetoplastida): its onset and contribution to the immunodepression. J. Fish Dis. (in press)

Thomas, P. T., Woo, P. T. K. (1990b). In vivo and in vitro cellmediated immune response of Oncorhynchus mykiss (Richardson) against Cryptobia salmositica (Sarcomastigophora: Kinetoplastida). J. Fish. Dis. (in press)

Woo, P. T. K. (1979). Trypanoplasma salmositica: experimental infections in rainbow trout, Salmo gairdneri. Expl Parasit. $47: 36-48$

Woo, P. T. K. (1987). Cryptobia and cryptobiosis in fishes. In: Baker, J. R., Muller, R. (eds.) Advances in parasitology, Vol. 26. Academic Press. London and New York, p. 199-237

Woo, P. T. K. (1990). MISET: an immunological technique for the serodiagnosis of Cryptobia salmositica (Sarcomastigophora: Kinetoplastida) infection in Oncorhynchus mykiss. J. Parasit. 76: 389-393

Woo, P. T. K., Li, S. (1990). In vitro attenuation of Cryptobia salmositica and its use as a live vaccine against cryptobiosis in Oncorhynchus mykiss. J. Parasit. 76: 752-755

Woo, P. T. K., Wehnert, S. D. (1983). Direct transmission of a haemoflagellate, Cryptobia salmositica (Kinetoplastida: Bodonina) between rainbow trout under laboratory conditions. J. Protozool. 30: 334-337

Manuscript first received: April 26, 1990

Revised version accepted: November 12, 1990 